\title{
How extensive is the effect of modern farming on bird communities in a sand dune desert?
}

\author{
Fares Khoury, Mohammed Al-Shamlih \\ Department of Biological Sciences, Hashemite University, P. O. Box 150459, Zarqa 13115, Jordan \\ Corresponding author: Fares Khoury (fkhoury@hu.edu.jo)
}

Academic editors: E. Neubert, Z. Amr | Received 7 March 2009 | Accepted 14 August 2009 | Published 28 December 2009

Citation: Khoury F, Al-Shamlih M (2009) How extensive is the effect of modern farming on bird communities in a sand dune desert? In: Neubert, E, Amr, Z, Taiti, S, Gümüs, B (Eds) Animal Biodiversity in the Middle East. Proceedings of the First Middle Eastern Biodiversity Congress, Aqaba, Jordan, 20-23 October 2008. ZooKeys 31: 211-219. doi: $10.3897 /$ zookeys.31.192

\begin{abstract}
Bird community structure and diversity measures in sand dune habitats far from and close to modern farms in Wadi Araba, south-west Jordan, were compared using 52 line transects for breeding birds and habitat variables.

A change in the bird community of sand dunes surrounding farming projects was measured to a distance of $1 \mathrm{~km}$, but could neither be related to changes in habitat structure nor to the activity of opportunistic predators (Red Fox) as these did not vary significantly between the two samples.

The farms included lines of trees and offered a constant source of water, which attracted a variety of opportunistic species, thus increasing bird diversity and total bird abundances.

The absence of characteristic ground-dwelling species of open sand dune habitats in the structurally intact sand dunes surrounding farms was likely to be the result of localized, but effectively far-reaching habitat modification (farms acting as barriers) and/or competition with some of the opportunistic species, which were common around farms.
\end{abstract}

\section{Keywords}

Hyper-arid desert, sand dunes, intensive agriculture, bird communities, Jordan.

\section{Introduction}

The anthropogenic impact on bird communities of arid ecosystems has been studied only tentatively. Most studies have focused on the effects of grazing, large irrigation projects and invasive plant species on ecosystem function and the diversity of ani- 
mals, including birds (Dean et al. 2002; Desmond 2003; Rahmani and Soni 1997; Whitford 1997).

The hyper-arid Wadi Araba in south-western Jordan exhibits a variety of habitat types ranging from sand dunes and alluvial fans to salt marshes and arid acacia savannahs. Although still considered as one of the least populated and spoilt areas of Jordan (Andrews 1995), current expansion of agricultural projects in Wadi Araba is probably interfering with ecosystem function and modifying the habitats of birds at an increasing rate. The aim of this study was to determine the impact of intensive agricultural practices on bird communities by comparing the community structure and diversity measures of sand dune habitats immediately surrounding farms with those, which are distant but of the same type. We tested a variety of approaches and analytical methods to determine the best indication of agricultural impact in arid landscapes using quantitative data on birds.

\section{Study area}

Wadi Araba, the northern extension of the Great Rift Valley, is a low-lying, flat strip of land between the mountain range of southwest Jordan and the Negev plateau of southern Israel. It stretches between the Gulf of Aqaba in the south and the Dead Sea in the north, with a maximum width of $30 \mathrm{~km}$. The study included the southern and central parts of the Jordanian side of Wadi Araba (c. 30 $\left.00^{\prime} \mathrm{N}, 35^{\circ} 10^{\prime} \mathrm{E}\right), 60 \%$ of which consists of sand dune desert. The climate is generally hot and hyper-arid; the mean annual precipitation is approximately $50 \mathrm{~mm}$, while the annual mean evaporation rate lies around $2.000 \mathrm{~mm}$ (National Atlas of Jordan, 1984). The occasional rainfalls usually occur during the winter months when temperatures are lower than in summer; temperatures range from $4{ }^{\circ} \mathrm{C}$ (absolute minimum) in the winter to $45^{\circ} \mathrm{C}$ in the summer, with an annual mean of $24^{\circ} \mathrm{C}$ (National Atlas of Jordan, 1984). Local disparities in soil and hydrological conditions cause a variety of vegetation and habitat types (Baierle, 1993). The sand dune habitats considered in this study vary from highly mobile sand dunes, nearly devoid of vegetation to more stable and flat sand dunes, where the surface is occasionally covered with a thin layer of fine gravel. The vegetation usually consists of a sparse cover dominated by Haloxylon persicum and a substantial annual cover after the rainy season. A few shallow waterbeds intercept the studied sites, which are lined with relatively dense vegetation dominated by $H$. persicum, and occasionally including the shrubs Calligonum comosum and Retama raetam. There are a few villages, in addition to nomadic Bedouins, but most of the area is unpopulated and considered a closed military zone due to its proximity to the political borders. Nevertheless, grazing by goats and camels of local Bedouins is permitted and widespread all over. Natural herbivores, e.g. Gazella dorcas, occur in small numbers near the borders with Israel. The establishment of large projects of intensive, irrigated farming is ongoing in several parts of the study area, which exploit ground water for irrigation and include fenced areas lined with introduced trees as windbreakers. 


\section{Materials and methods}

\section{Field methods}

Quantitative data on birds was collected using the line transect method (Bibby et al. 2000) in the period from March to May 2004, which covered the major part of the breeding season. Thirty-seven line transects were randomly selected in sand dune habitats at distances ranging from 0.5 to $8 \mathrm{~km}$ from the nearest farms. Each line transect was $1 \mathrm{~km}$ in length, with a belt of $100 \mathrm{~m}$ on each side. In addition, 15 line transects were carried out in the same habitat type close to farms. In these cases, the observers walked parallel to and at a distance of 80-100 $\mathrm{m}$ from the farm fence, thus additionally covering the birds seen at the border of the farms. The individual farms covered areas ranging from $0.5-5 \mathrm{~km}^{2}$, and most had a narrow rectangular shape, with a length exceeding $1 \mathrm{~km}$, thus allowing us to carry out full transects parallel to their borders. Line transects were carried out from sunrise to 10:00 am; the duration of each transect ranged from 25-35 minutes, during which all of the birds within the 100-m belts were recorded by two observers walking parallel, at a distance of $20 \mathrm{~m}$. We excluded in the analysis all bird species that do not breed in the study area, e.g. migrants and birds resident and breeding in different habitat types in neighbouring areas, which occasionally utilised the study area for feeding, as well as birds detected beyond $100 \mathrm{~m}$ and those just flying over the transects. Habitat variables were quantified at three points (at the two ends and at the middle) along each line transect to a range of $50 \mathrm{~m}$ before being averaged. This allowed a general description and comparison of the habitats of the two groups of samples (far and close). Additionally, the activity of mammalian predators (mainly the opportunistic red fox Vulpes vulpes) was determined by counting the number of trails crossing the sandy surface of line transects.

\section{Data analysis}

Analysis conducted at the community level included the construction of dendrograms of the samples (line transects), using group-average clustering from Bray-Curtis similarities on log-transformed bird abundances (Clarke and Warwick 2001, Khoury and Al-Shamlih 2006)). Diversity measures were calculated for all samples (transects) in each group (far and close) and included species richness ( $S=$ number of species), Shannon-Wiener index $(H)$ and evenness $(J)$. The calculations were according to the following formulas:

$$
H=\sum_{i=1}^{s} P i \ln P i \quad J=H / H \max
$$

Where $s$ is the number of species present in the sample; $P i$ is the proportion of species $i$ in the sample of $s$ species; $H \max =\ln s$.

The diversity measures and total number of individuals of the two samples (Far and close) were tested for significant differences using the non-parametric Mann-Whitney U-test, as they departed from normality. Analysis of variance (ANOVA) was applied 
to examine differences in the habitat variables between the two samples. The impact of agriculture on bird assemblages was further analysed by comparing the total number of individuals belonging to bird species originally native to Wadi Araba and referred to as "naturally occurring" with the number of "opportunistic"|"agricophilic" birds, which benefited from agricultural expansion as indicated by their range expansion into the general area in previous decades (Table 1; Andrews 1995; Shirihai 1996). Other species, which are locally expanding their range due to agricultural developments, were included in the first group, as they are known to belong to the original avifauna of natural habitats in Wadi Araba (Andrews 1995). These are referred to in Table 1 as agriculture-enhanced. Trumpeter Finch, for example originally occurs in natural habitats in Wadi Araba where a mix of sand and stones or rocks cover the ground, however this species has apparently benefited locally from agriculture (Shirihai 1996); Desert finches are classified as opportunistic because they invaded Wadi Araba consequent to agricultural developments, i.e. they did not previously breed in Wadi Araba. We used the t-test to compare the number of "naturally occurring" and "opportunistic" species in each sample group (far and close).

Table I. The classification of birds as agriculture-sensitive and agriculture-enhanced (="naturally occurring") and "opportunistic" or "agricophilic". The mean abundances $( \pm$ S.E.) are shown for transects distant from (F-transects, $>0.5 \mathrm{~km}$ ) and adjacent to farms (C-transects, $\leq 0.2 \mathrm{~km}$ ).

\begin{tabular}{|c|c|c|c|}
\hline \multirow[b]{2}{*}{ Agriculture-sensitive } & \multirow[t]{2}{*}{ F-transects $(n=37)$} & \multicolumn{2}{|c|}{ C-transects $(n=15)$} \\
\hline & & & \\
\hline Spotted Sandgrouse Pterocles senegallus & $0.14 \pm 0.09$ & 0 & \\
\hline Bar-tailed Lark Ammomanes cincturus & $0.51 \pm 0.22$ & 0 & \\
\hline Thick-billed Lark Ramphocoris clotbey & $0.05 \pm 0.05$ & 0 & \\
\hline Temminck's Lark Eremophila bilopha & $0.14 \pm 0.09$ & 0 & \\
\hline Hoopoe Lark Alaemon alaudipes & $1.81 \pm 0.26$ & 0 & \\
\hline Desert Wheatear Oenanthe deserti & $0.55 \pm 0.13$ & 0 & \\
\hline \multicolumn{4}{|l|}{ Agriculture-enhanced } \\
\hline Little Green Bee-eater Merops orientalis & $0.19 \pm 0.09$ & $1.40 \pm 0.52$ & $* *$ \\
\hline Spectacled Bulbul Pycnonotus xanthopygos & $0.05 \pm 0.05$ & $4.13 \pm 0.96$ & $* * *$ \\
\hline Great Grey Shrike Lanius excubitor & $0.08 \pm 0.06$ & 0 & \\
\hline Palestine Sunbird Nectarina osea & 0 & $0.07 \pm 0.07$ & \\
\hline Trumpeter Finch Bucanetes githagineus & $0.08 \pm 0.06$ & 0 & \\
\hline \multicolumn{4}{|l|}{ opportunistic/agricophilic } \\
\hline Collared Dove Streptopelia decaocto & $0.86 \pm 0.23$ & $8.20 \pm 2.14$ & $* * *$ \\
\hline Laughing Dove Streptopelia senegalensis & $0.14 \pm 0.10$ & $2.40 \pm 1.39$ & $* *$ \\
\hline Crested Lark Galerida cristata & $0.78 \pm 0.12$ & $1.73 \pm 0.46$ & ** \\
\hline Rufous Bush Robin Cercotrichas galactotes & 0 & $0.47 \pm 0.13$ & \\
\hline Graceful Warbler Prinia gracilis & 0 & $1.20 \pm 0.46$ & \\
\hline Desert Finch Rhodospisa obsoleta & $0.08 \pm 0.06$ & $0.20 \pm 0.14$ & \\
\hline House Sparrow Passer domesticus & $0.11 \pm 0.11$ & $6.13 \pm 1.29$ & $* * *$ \\
\hline
\end{tabular}

** $p<0.01 ;{ }^{* * *} p<0.001$. 


\section{Results}

A comparison of the habitat variables and red fox activity in the sand dune habitats far from farm (hereafter referred to as F-transects) with those close to farms (C-transects) showed that the two groups did not differ significantly in habitat structure or in the activity of red foxes (ANOVA, $p>0.05$ for all habitat variables, Table 2). However, the borders of the farms, which included fences and planted trees, were excluded from this analysis. This lead to the conclusion, that the impact of agriculture on the immediate surroundings is due to indirect factors produced by farming practices rather than a direct modification of habitat structure. Although it is likely that farming activities cause a general increase in the abundance of red foxes in the whole study area, there was no significant difference in its activity and assumed effect on birds when F-transects and C-transects were compared $(p>0.05)$.

The C-transects had significantly higher Shannon indices and species richness than F-transects (U-Test, $p<0.001$ in both cases, Table 2), although characteristic species of sandy habitats were completely absent in the C-transects. These were replaced in the surrounding sandy habitats and at the edges of farms by a number of "opportunistic" species. In addition, the total avian abundance was significantly higher around and at the edges of farms when compared to the relatively unaffected sand dune habitats, or F-transects (U-test, $p<0.001$ ).

Table 2. The means ( \pm S.D.) of habitat variables, diversity indices, total number of individuals of all birds and number of individuals belonging to "naturally occurring" and "opportunistic" bird species in the transects far from farms (F-transects) and those close to farms (C-transects).

\begin{tabular}{l|c|c}
\hline Habitat variables/indices & F-transects & C-transects \\
\hline $\mathrm{N}$ & 37 & 15 \\
\hline Ground cover & & \\
\hline Rock & $0.1 \pm 0.3$ & $0.5 \pm 0.6$ \\
\hline Sand & $92.4 \pm 14.9$ & $95.7 \pm 8.9$ \\
\hline Stone & $4.2 \pm 4.0$ & $1.3 \pm 0.1$ \\
\hline Gravel & $3.3 \pm 3.1$ & $2.5 \pm 1.8$ \\
\hline Vegetation cover & $3.1 \pm 4.0$ & \\
\hline Herbaceous & $2.1 \pm 2.2$ & $1.0 \pm 1.7$ \\
\hline Dwarf Shrubs & $10.9 \pm 9.1$ & $1.6 \pm 3.3$ \\
\hline Shrubs & $3.2 \pm 1.7$ & $5.8 \pm 11.4$ \\
\hline Species richness & $0.4 \pm 0.2$ & $0.6 \pm 0.1^{* * *}$ \\
\hline Shannon diversity & $0.4 \pm 0.2$ & $0.7 \pm 0.1$ \\
\hline Evenness & $6.2 \pm 4.5$ & $25.7 \pm 12.2^{* * *}$ \\
\hline Total number of individuals & $3.8 \pm 3.3$ & $1.3 \pm 2.2$ \\
\hline Number of individuals of "naturally occurring" birds & $2.0 \pm 2.7 *$ & $24.3 \pm 19.1$ ** \\
\hline Number of individuals of "opportunistic" birds
\end{tabular}

${ }^{*} p<0.05 ;{ }^{* *} p<0.01 ;{ }^{* * *} p<0.001$ 


\section{Sample clusters and bird assemblages}

The 52 line transects produced 18 species of breeding birds (Table 1), some of which were present in both samples (far and close). In the dendrogram based on Bray-Curtis similarity coefficients, two large clusters emerged, separating at a similarity coefficient of $10 \%$. The first cluster (Fig. 1, left) included $81 \%$ of the F-transects, which diverged to smaller subgroups at various similarity levels above $30 \%$. The subdivisions were probably the result of local variations in the sand dune habitat affecting bird species composition. The second cluster (Fig. 1, right) included all C-transects, which also diverged to several subgroups. However, one subgroup (extreme right, Fig. 1) was formed by $88 \%$ of the C-transects, which was separated from other transects at a similarity level of 55\%. A few F-transects included "opportunistic" species like the Crested Lark and were located within a distance of $1 \mathrm{~km}$ to farms (except F3, Fig. 1), thus they appeared in the dendrogram closer to the C-transects. This indicated a gradient of effects on bird assemblages in sand dune habitats ranging to a distance of around $1 \mathrm{Km}$ from the borders of farms.

Ground-dwelling species, Hoopoe Lark and Desert Wheatear, which co-occurred locally with the Bar-tailed Lark, Spotted Sandgrouse and other, less frequent species were described as agriculture-sensitive species (Table 1) and were completely absent around farms to a distance of more than $200 \mathrm{~m}$ (Table 3). C-transects were clustered together according to the opportunistic and agriculture-enhanced species (Table 1) that have recently colonised the general area or have locally expanded their distribution subsequent to agricultural development. Except for the Crested Lark, all of these species are known to use shrubs and trees. Some, especially Collared Dove and Little Green Bee-eater also occurred in a number of F-transects, but usually at lower frequency and abundances.

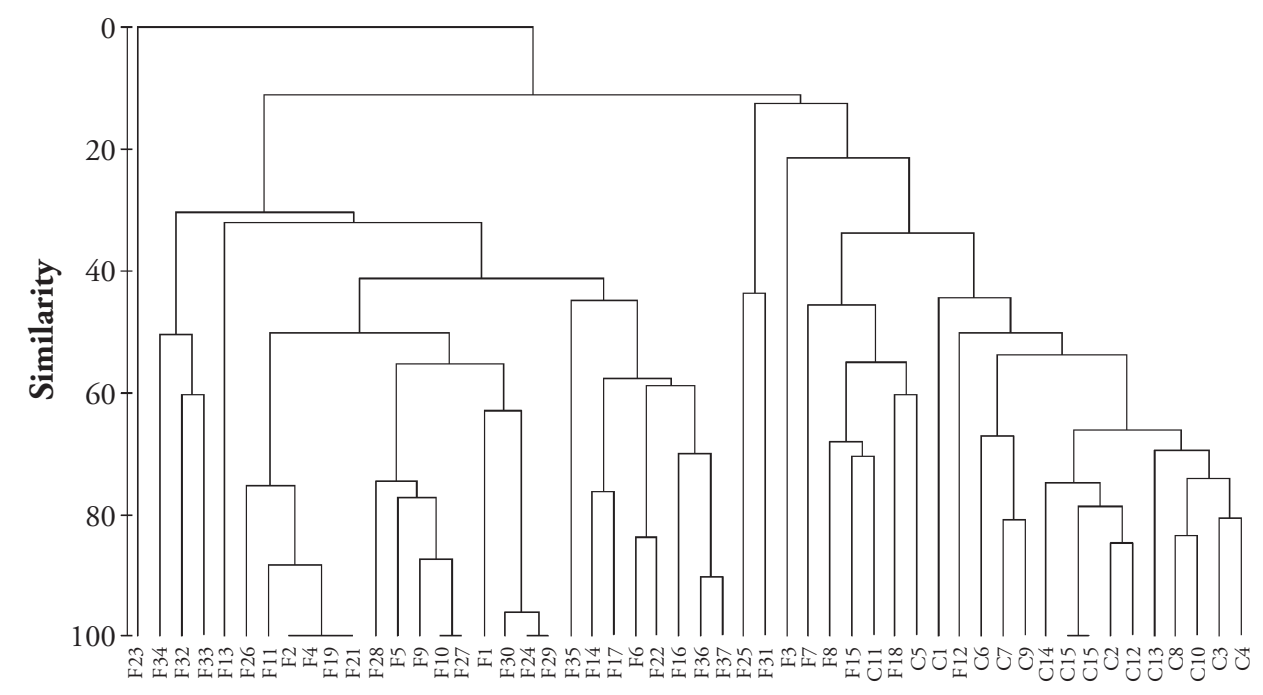

Figure I. Dendrogram of F- and C-transects, using group-average clustering from Bray-Curtis similarities on log-transformed bird abundances. Similarity coefficient in percent. 
Table 3. The means $( \pm \mathrm{SE})$ of abundances of two common sensitive species (HL= Hoopoe lark, $\mathrm{DW}=$ Desert wheatear) and two opportunistic species $(\mathrm{CD}=$ Collared dove, $\mathrm{CL}=$ Crested lark) at varying distances from farms: C: $0-0.2 \mathrm{~km} ; \mathrm{F} 1: 0.5-2.5 ; \mathrm{F} 2: 2.7-8 \mathrm{~km}$.

\begin{tabular}{l|c|c|c|c|}
\hline & HL & DW & CD & CL \\
\hline $\mathrm{C}(n=15)$ & 0 & 0 & $8.20 \pm 2.14$ & $1.73 \pm 0.46$ \\
\hline $\mathrm{F} 1(n=19)$ & $1.26 \pm 0.30$ & $0.42 \pm 0.16$ & $1.05 \pm 0.40$ & $0.74 \pm 0.33$ \\
\hline $\mathrm{F} 2(n=18)$ & $2.39 \pm 0.38$ & $0.68 \pm 0.20$ & $0.67 \pm 0.23$ & $0.11 \pm 0.08$ \\
\hline & $*$ & & $* * *$ & $* * *$ \\
\hline Threshold distance. $\mathbf{k m}$ & $\mathbf{0 . 9}$ & $\mathbf{0 . 9}$ & & \\
\hline
\end{tabular}

${ }^{*} p<0.05,{ }^{* *} p<0.01,{ }^{* *} p<0.001$; U-test for two samples (HL, DW) and Kurskal-Walis test for multiple samples (CD, CL). Threshold distance represents the distance of the nearest transect to farms, in which sensitive species were recorded.

\section{Discussion}

The cluster analysis comparing the line transects in sandy habitats close to farms and far from farms confirmed the impact of intensive farming on bird assemblages. In general, transects with similar bird assemblages clustered together and a major split was observed between most F- and C-transects. A few F-transects were similar to Ctransects, indicating a gradient of agricultural effects to a distance of $1 \mathrm{~km}$ into the surrounding sand dune habitats. Most of these transects contained a relatively dense shrub cover, thus supporting larger numbers of a few species also occurring along the edges of farms, e.g. Collared Dove and Little Green Bee-eater, and lower numbers of grounddwelling species of the open sand dune habitat. The bird community of the sand dunes in Wadi Araba is split into two main clusters (Khoury and Al-Shamlih 2006): the first included agriculture-sensitive species, which inhabit unaffected sand dune habitats and avoided structurally intact sand dunes surrounding farms, whereas the second cluster includes species which benefit from intensive, irrigated farming activities.

Intensive farming in Wadi Araba is interfering in the natural processes of the arid ecosystem, as indicated by the local decline of characteristic desert species. Such species were found to be sensitive to intensive agriculture, although farming activities artificially increased productivity, including food resources and water availability that, on the other hand, significantly augmented the number of opportunistic species and total avian abundance in the $\mathrm{C}$-transects.

On the Jordanian side of Wadi Araba, modern farms still cover a small proportion of the general area, although they are currently increasing in number and area. Being fenced and secluded, these farms did not directly change the habitat structure of the surroundings. Nonetheless, a complete absence of characteristic ground-dwelling species in the structurally intact sand dunes was notable to a distance of several hundred meters around farms. Knick and Rotenberry (1995) have previously shown that many characteristic birds of open habitats (core species) avoid marginal sites, which are close to the edges of their natural habitats. There was no evidence for a localized effect 
of the opportunistic, predatory red fox on bird assemblages, as the activity of red foxes was approximately the same over the whole area. The absence of the typical desert species was probably because they avoid vertical structures (tree lines) forming barriers, which limit daily movements and obscure vision important for display, efficient foraging and predator avoidance. Another possible effect is competition with opportunistic species, particularly the Crested Lark, which was found in F-transects, mainly within a distance of $2.5 \mathrm{~km}$ from the borders of the nearest farm. There was no further evidence for any other effects, e.g. the use of pesticides, which may however affect opportunistic species more severely, as they would be directly exposed (Mclaughin and Mineau 1995).

\section{Acknowledgements}

We thank Khaled Nassar, Hatim Sultan and Rami Awad from the Jordanian Society for Sustainable Development for their assistance in field work and logistic support.

\section{References}

Al-Shamlih M, Nassar K, Khoury F (in press) Distribution and habitat association of selected breeding species in Wadi Araba, Jordan. Sandgrouse.

Andrews IJ (1995) The Birds of the Hashemite Kingdom of Jordan. Musselburgh. 185 pp.

Baierle HU (1993) Vegetation und Flora im sudwestlichen Jordanien. Dissertationes Botanicae, Vol. 200. Berlin. 254 pp.

Bibby CJ, Burgess ND, Hill DA, Mustoe S (2000) Bird Census Techniques. 2nd edition. Academic Press. 302 pp.

Clarke KR, Warwick RM (2001) Change in Marine Communities: An Approach to Statistical Analysis and Interpretation. 2nd edition. PRIMER-E Ltd. 180 pp.

Dean WRJ, Anderson MD, Milton SJ, Anderson TA (2002) Avian assemblages in native Acacia and alien Prosopis drainage line woodland in the Kalahari, South Africa. J. arid environ. 51: 1-19.

Desmond M (2004) Effects of grazing practices and fossorial rodents on a winter avian community in Chihuahua, Mexico. Biol. Conserv., 116(2): 235-242.

Khoury F (2001) On the breeding bird community of Wadi Al-Kharrar, Jordan Valley. Zool. Middle East, 22: 37-44.

Khoury F (2006): The impact of intensive agriculture on the bird community of a sand desert. J. arid environ. 64: 448-459.

Knick ST, Rotenberry JT (1995) Landscape characteristics of fragmented shrubsteppe habitats and breeding passerine birds. Conserv. Biol., 9(5): 1059-1071.

Mclaughin A, Minneau P (1995) The impact of agricultural practices on biodiversity. Agric., ecosys. and environ., 55: 201-212.

National Atlas of Jordan (1984) Climate and Agriclimatology. Jordan Nat. Geogr. Center, Amman. 
Rahmani AR, Soni RG (1997) Avifaunal changes in the Indian Thar Desert. J. arid environ., 36: 687-703.

Shirihai H (1996) The Birds of Israel. Academic Press. 692 pp.

Whitford WG (1997) Desertification and animal biodiversity in the desert grasslands of North America. J. arid environ., 37: 709-720. 